\title{
The relationship between body mass index, body composition and premenstrual syndrome prevalence in girls
}

\author{
Malgorzata Mizgier ${ }^{1}$, Grazyna Jarzabek-Bielecka², Ewa Jakubek³ , Witold Kedzia² \\ ${ }^{1}$ Department of Morphological and Health Sciences, Dietetic Division, Faculty of Physical Culture in Gorzow Wielkopolski, \\ Poznan University of Physical Education, Poland \\ ${ }^{2}$ Division of Developmental Gynecology and Sexology, Department of Perinatology and Gynecology, \\ Poznan University of Medical Sciences, Poland \\ ${ }^{3}$ Department of Law, Organization and Managemant in Healthcare, Faculty of Health Sciences, \\ Poznan University of Medical Sciences, Poland
}

\begin{abstract}
Objectives: Premenstrual Syndrome (PMS) is a cluster of physical and emotional symptoms occurring in the luteal phase of the menstrual cycle. The study aim was to determine the relationship between PMS, and state of nutrition expressed as Body Mass Index (BMI) and body composition in 18-year-old females.

Material and methods: The study was conducted on 476 women divided into two groups i.e. those suffering from PMS $(n=233)$ and those without symptoms $(n=243)$. The women were examined during their luteal phase using bioelectrical impedance analysis to determine their body composition. Height and weight were measured using digital medical scales with an electronic height rod. BMI was calculated thus: BMI = body mass (weight) $(\mathrm{kg}) / \mathrm{height}\left(\mathrm{m}^{2}\right)$. The subjects were divided into two sub-groups: $\mathrm{BMI}<25 \mathrm{~kg} / \mathrm{m}^{2}$ and $\mathrm{BMI} \geq 25 \mathrm{~kg} / \mathrm{m}^{2}$. Statistical analysis was carried out using STATISTICA $10 \mathrm{PL}$ software and the Mann-Whitney test.

Results: The women with normal BMI suffered from PMS twice as often as the women with $B M I \geq 25 \mathrm{~kg} / \mathrm{m}^{2}$ (68.2\% vs. $\left.31.8 \%\right)$. There were significantly higher values for Fat Mass (FM) $(\%)(p<0.01)$ and FM $(\mathrm{kg})(\mathrm{p}<0.001)$ in women without PMS, and significantly higher values for Fat-Free Mass (FFM) (\%) $(p<0.001)$ and Total Body Water (TBW) $(\%)(p<0.001)$ in women with PMS. Higher values were reported for FFM $(\mathrm{kg})$ and TBW $(\mathrm{kg})(\mathrm{p}<0.05)$ in girls with PMS and BMI $\geq 25$.

Conclusions: These results show PMS is more frequent in patients with $\mathrm{BMI}<25$, and less frequent in patients with higher FM (kg) and FM (\%). Moreover, significant frequency of PMS was observed in patients with higher FFM and TBW. Such statistical significance was not confirmed in girls with a $\mathrm{BMI}<25$.
\end{abstract}

Key words: premenstrual syndrome; gynaecology; body composition

Ginekologia Polska 2019; 90, 5: 256-261

\section{INTRODUCTION}

Premenstrual Syndrome (PMS) is a cluster of somatic, emotional and behavioural symptoms occurring in the luteal phase of the menstrual cycle. Many studies have been conducted but the aetiology of PMS remains unknown [1-3]. PMS symptoms substantially affect the quality of a woman's life [2, 3].

According to strict diagnostic criteria, an estimated $2.5-5 \%$ of girls and women are affected by PMS. However, some researchers maintain that the symptoms of PMS may be prevalent in as many as $40-80 \%$ of girls and women. Due to this considerable discrepancy, it is necessary to make the definition of PMS more precise. Patients with PMS experience mood disturbances together with physical and emotional symptoms, which recur in the luteal phase and disappear in the follicular phase of the menstrual cycle. No other psychiatric or health conditions that might cause similar symptoms are observed. The symptoms, with irritability being a major one, occur to a degree that they impair some aspects of a women's life, in particular, their sexuality. Such 
symptoms usually last from 10 to 14 days every month. The basic diagnostic criteria for PMS include:

1. Prospectively establishing the timing of the symptoms, confirmed by prospective daily ratings for at least two menstrual cycles, with changes documented in a diary (at least one affective or physical symptom during the last five days before menses and remission of the symptoms within the first four days of the menses).

2. A $30 \%$ increase in the intensity of symptoms in the luteal phase, as compared with the follicular phase.

It is made sure that the subjects do not have histories of psychiatric disorders or hormonal medication such as oral contraceptive pills or irregular menstrual cycles. The most common PMS symptoms include physical symptoms: breast tenderness or breast pain (mastalgia), accompanied by breast swelling and tenderness of the nipples (70\%), abdominal pains, bloating, abdominal swelling and sometimes constipation (50\%), headaches and migraines (30\%), swelling and weight gain (45\%), cramps and back pains, dizziness, digestive disturbances, nausea, vomiting, diarrhoea, swelling of extremities (both hands and feet), joint or muscle pain, palpitations, frequent micturition, increased thirst, decreased alcohol tolerance, and skin lesions. Symptoms of chronic diseases are frequently aggravated e.g. allergic symptoms, including hay fever, bronchial asthma and allergic dermatitis, chronic digestive disorders and nervous system diseases (e.g. epilepsy). Other psychologic and behavioural PMS symptoms include: sugar and salt cravings, tension or anxiety, irritability, crying and tearfulness, fatigue, depressed mood, insomnia or hypersomnia, forgetfulness or confusion, panic attacks, aggression and depression [4-9].

The prevalence of PMS is related to the ovarian cycle and the influence of oestrogen and progesterone on centrally acting neurotransmitters, serotonin and GABA ( $\gamma$-aminobutyric acid). Arguing for this hypothesis is that PMS is not prevalent before puberty, during pregnancy and after menopause. Oestrogen and progesterone influence serotonin receptors. The evidence suggests that treatment with selective serotonin reuptake inhibitors (SSRI PMS) alleviates PMS symptoms. Allopregnanolone, a metabolite of progesterone, modulates GABA and symptomatic women seem to have lower levels of allopregnanolone. Some studies find that PMS may be determined by genetic factors; however, no specific genotype has been identified yet. Childhood emotional experiences are linked with PMS prevalence in adulthood. In addition, the occurrence of PMS is influenced by lifestyle (physical activity, diet), personality disorders and addiction to psychoactive substances, as well as high body mass index (BMI) [10-21].

Research has been going on for many years on the changes in body composition that are related to age, malnutrition or overnutrition. However, to our knowledge, no previous studies have examined whether body composition may be a premenstrual syndrome indicator in young women.

In this study, bioelectrical impedance analysis (BIA) was used to assess body composition of the patients [1]. BIA is a non-invasive diagnostic method using the ability of tissues to impede electric current and providing accurate analysis of body composition. BIA approach is also used in total body water and fat content measurements $[1,4]$.

Techniques for assessing body composition emerged in the first half of the 20th century. Initially, an indirect way of this assessment relied on the analysis of body fluids. The discovery of deuterium enabled accurate assessment of total body water, and the use of other isotopes of hydrogen helped to develop assessment techniques of totally replaceable electrolytes - sodium and potassium. The early studies by Barnett and other investigators focused on the relationship between bioelectrical impedance measurements and total body water. In the 1970's, Nyboer et al. started their pioneer research on impedance plethysmography, in which they highlighted the relationship between the changes in body impedance and the changes in pulsatile blood, pulse and breathing. Simultaneously, hydrodensitometry was being investigated as a method of estimating body composition. At the time, most of the body mass measurement methods relied on the distinction between the two main components i.e. fat and non-fatty matter. Hydrodensitometry apparatus became standard equipment for measuring body composition. A distinction was made between fat mass (FM) and fat-free mass (FFM). Fat mass components include triglycerides and lipids but no water or potassium. The composition of fat-free mass include $72-74 \%$ of water and 60-66 mmol/kg of potassium. This 2-compartment model became a basis for the modern research on body composition. In the years that followed, a 4-compartment model was developed which divided the body into measured water, protein, bones, mineral mass (ash mass) and fat. As in the 2-compartment model, total body potassium (TBK) measurements and total body water (TBW) measurements were used to estimate body components. The division based on TBK and TBW measurements led to the development of the 4-compartment model. The 4-compartment model includes: FM, BCM (Body Cell Mass), ECW (extracellular water; in girls about $45 \%$ of TBW) and other fat-free extracellular solids (FFECS). Later on, intracellular water (ICW), which constitutes approximately $55 \%$ of total body water, was distinguished from ECW. Bioelectrical impedance (BIA) was first used in the mid-1980s. Today many BIA devices are in use, with different electrode configurations and different frequencies [1, 4].

The objective of the present study was to investigate the relationship between state of nutrition, expressed as BMI, body composition in 18-year-old girls, and premenstrual syndrome prevalence. 


\section{MATERIALS AND METHODS}

The study was conducted among the patients of Gynaecology and Perinatology Medical Centre in Gynaecology and Obstetrics Hospital of Poznan University of Medical Sciences. The sample of 476 Caucasian women aged 18 was divided into two groups: experimental one with PMS ( $n=233)$ and controls without PMS $(n=243)$.

Diagnosis of PMS in this study was made according to the diagnostic criteria suggested by Royal College of Obstetricians and Gynaecologists (RCOG) [16].

Testing for PMS included a symptom diary in which the patients prospectively recorded the symptoms within two full monthly cycles.

PMS was diagnosed if the patient reported at least one of the following symptoms including depression, irritability, anxiety, confusion or social withdrawal and one of the somatic symptoms (breast tenderness, abdominal bloating, headache, swelling of extremities) during the 5 days before menses in the two prior menstrual cycles. The patients were diagnosed by a practitioner during the medical examination.

Exclusion criteria were based on the exclusion of disease entities that could be similar to PMS, i.e. mental disorders such as depression, bipolar disorder, anxiety and personality disorders, as well as drug dependence, endometriosis, thyroid function disorders, allergies, and autoimmune diseases [17].

Body composition was assessed with Tanita MC 780 device which uses bioelectrical impedance analysis (BIA method) [4]. In this model, the accuracy of measurement for the individual components, including adipose tissue, is 100 grams. The measurements of fat mass FM, fat-free mass FFM and total body water TBW have been expressed as percentage (\%) and kilograms (kg). All the patients had their height and body mass measured. Weight was measured to the nearest $0.1 \mathrm{~kg}$ using a SECA 899 digital medical scales. Height was measured to the nearest $\mathrm{mm}$ with a SECA 217 stadiometer attached to the scales. The patients were asked to remove their shoes and outer garments.

The measurements were taken according to the standards for anthropometric assessment (The World Health Organisation, 1987). BMI was calculated as weight in kilograms divided by height in metres squared $\left(\mathrm{kg} / \mathrm{m}^{2}\right)$.

The participants were grouped according to their BMI: $<25 \mathrm{~kg} / \mathrm{m}^{2}$ and $\mathrm{BMI} \geq 25 \mathrm{~kg} / \mathrm{m}^{2}$.

Statistical analysis was carried out using STATISTICA $10 \mathrm{PL}$ software. Due to non-normal distribution and inability to ensure constant homogeneity of variances, Mann-Whitney test was used to assess parametric differences in PMS and non-PMS women. Statistical significance was set at $P<0.5$.

Before the study began, all the patients had been informed about the procedures, aims, and scope of the study. Informed consent was obtained from all the partici-

\begin{tabular}{|c|c|c|c|c|}
\hline \multirow{3}{*}{ BMI in $\mathrm{kg} / \mathrm{m} 2$} & \multicolumn{4}{|c|}{ prevalence of PMS } \\
\hline & \multicolumn{2}{|c|}{$\begin{array}{l}\text { yes } \\
n=233\end{array}$} & \multicolumn{2}{|c|}{$\begin{array}{l}\text { no } \\
n=243\end{array}$} \\
\hline & $\mathbf{n}$ & [\%] & $\mathbf{n}$ & [\%] \\
\hline$<25$ & 159 & 68.2 & 127 & 52.3 \\
\hline$\geq 25$ & 74 & 31.8 & 116 & 47.7 \\
\hline
\end{tabular}

Source: authors' own research

pants. The study was approved by the Bioethics Committee of Karol Marcinkowski Poznan University of Medical Sciences (Resolution No 553/18).

\section{RESULTS}

The study was conducted among 476 women aged 18 who were divided two groups: women with PMS $(n=233)$ and those without PMS $(n=243)$. Then, two sub-groups were identified: women with $\mathrm{BMI}<25 \mathrm{~kg} / \mathrm{m}^{2}$ and women with $\mathrm{BMI} \geq 25$ (Tab. 1). It was observed that among the women with normal body mass (BMI $\left.<25 \mathrm{~kg} / \mathrm{m}^{2)}\right)$, twice as many had PMS, compared to those with a BMI $\geq 25$ (68.2 vs. 31.8).

Statistically significant differences between PMS and non-PMS groups are given in Table 2.

The parameters for analysis included: fat mass (FM), fat-free mass (FFM) and total body water (TBW), expressed as percentage and kilograms.

There were statistically significant differences between the PMS and non-PMS groups for FM, expressed as percentage and kilograms, with significantly higher values for women without PMS $(p=0.001$ and $p=0.0001$ respectively). Higher values for FFM (\%) $(p=0.0001)$ and TBW (\%) ( $p=0.0001)$ were reported for women with PMS.

As shown in Table 3, there was no statistically significant difference in the examined parameters between trials in women with PMS and the control group with normal body mass i.e. $\mathrm{BMI}<25$.

Body composition of the two groups in patients with $\mathrm{BMI} \geq 25$ was compared. Statistically significant differences were observed. In women with PMS, higher values were recorded both for FFM $(\%)(p=0.02)$ and TBW $(k g)(p=0.02)$ (Tab. 4).

\section{DISCUSSION}

In the present study we have assessed the state of nutrition and body composition in 18-year-old girls, with the use of BMI and BIA respectively. The objective of the study was to determine the relationship between $\mathrm{BMI}$, fat mass, fat-free mass and water with PMS prevalence.

Our study reported that there was a statistically significant relationship between PMS and BMI. PMS is significantly 


\begin{tabular}{|c|c|c|c|c|c|c|c|c|c|}
\hline \multirow{2}{*}{ Parameter } & \multirow{2}{*}{ PMS prevalence } & \multirow{2}{*}{$\mathbf{n}$} & \multirow{2}{*}{ Mean } & \multirow{2}{*}{ SD } & \multirow{2}{*}{ Median } & \multirow{2}{*}{ Min. } & \multirow{2}{*}{ Max. } & \multicolumn{2}{|c|}{ Mann-Whitney test } \\
\hline & & & & & & & & $\mathbf{z}$ & p \\
\hline \multirow{2}{*}{$\mathrm{FM}[\mathrm{kg}]$} & yes & 233 & 20.2 & 10.1 & 17.3 & 2.1 & 61.5 & \multirow{2}{*}{-3.29} & \multirow{2}{*}{$0.001^{*}$} \\
\hline & no & 243 & 23.0 & 10.8 & 21.2 & 2.1 & 61.7 & & \\
\hline \multirow{2}{*}{ FM [\%] } & yes & 233 & 29.2 & 8.2 & 28.3 & 5.7 & 50.1 & \multirow{2}{*}{-3.96} & \multirow{2}{*}{$0.0001^{*}$} \\
\hline & no & 243 & 32.0 & 8.8 & 32.1 & 5.0 & 53.7 & & \\
\hline \multirow{2}{*}{$\mathrm{FFM}[\mathrm{kg}]$} & yes & 233 & 45.7 & 6.6 & 44.3 & 28.7 & 70.5 & \multirow{2}{*}{-0.35} & \multirow{2}{*}{ ns } \\
\hline & no & 243 & 45.4 & 5.5 & 45.2 & 30.8 & 65.9 & & \\
\hline \multirow{2}{*}{ FFM [\%] } & yes & 233 & 70.8 & 8.2 & 71.7 & 50.0 & 94.4 & \multirow{2}{*}{3.96} & \multirow{2}{*}{$0.0001^{*}$} \\
\hline & no & 243 & 68.0 & 8.8 & 67.9 & 46.3 & 95.0 & & \\
\hline \multirow{2}{*}{ TBW [kg] } & yes & 233 & 33.5 & 4.8 & 32.4 & 21.0 & 51.6 & \multirow{2}{*}{-0.35} & \multirow{2}{*}{ ns } \\
\hline & no & 243 & 33.2 & 4.0 & 33.1 & 22.6 & 48.2 & & \\
\hline \multirow{2}{*}{ TBW [\%] } & yes & 233 & 51.8 & 6.0 & 52.4 & 36.6 & 69.0 & \multirow{2}{*}{3.95} & \multirow{2}{*}{0.0001} \\
\hline & no & 243 & 49.8 & 6.5 & 49.6 & 33.8 & 69.5 & & \\
\hline
\end{tabular}

*statistically significant, $\mathrm{p}<0.05$; ns - not statistically significant; SD — standard deviation

Source: authors' own research

\begin{tabular}{|c|c|c|c|c|c|c|c|c|c|}
\hline \multirow{2}{*}{ Parameter } & \multirow{2}{*}{ Prevalence of PMS } & \multirow{2}{*}{ n } & \multirow{2}{*}{ Mean } & \multirow{2}{*}{ SD } & \multirow{2}{*}{ Median } & \multirow{2}{*}{ Min. } & \multirow{2}{*}{ Max. } & \multicolumn{2}{|c|}{ Mann-Whitney test* } \\
\hline & & & & & & & & $\mathbf{Z}$ & $p$ \\
\hline \multirow{2}{*}{$\mathrm{FM}[\mathrm{kg}]$} & yes & 159 & 14.92 & 4.49 & 14.70 & 2.10 & 28.10 & \multirow{2}{*}{-0.49} & \multirow{2}{*}{ ns } \\
\hline & no & 127 & 15.26 & 5.32 & 15.20 & 2.10 & 27.80 & & \\
\hline \multirow{2}{*}{ FM [\%] } & yes & 159 & 25.18 & 5.52 & 25.50 & 5.70 & 36.20 & \multirow{2}{*}{-1.07} & \multirow{2}{*}{ ns } \\
\hline & no & 127 & 25.70 & 6.41 & 26.70 & 5.00 & 38.60 & & \\
\hline \multirow{2}{*}{$\mathrm{FFM}[\mathrm{kg}]$} & yes & 159 & 43.48 & 5.26 & 42.70 & 28.70 & 70.50 & \multirow{2}{*}{0.67} & \multirow{2}{*}{ ns } \\
\hline & no & 127 & 42.63 & 3.85 & 42.40 & 30.80 & 54.30 & & \\
\hline \multirow{2}{*}{ FFM [\%] } & yes & 159 & 74.85 & 5.56 & 74.58 & 63.74 & 94.39 & \multirow{2}{*}{1.08} & \multirow{2}{*}{ ns } \\
\hline & no & 127 & 74.31 & 6.40 & 73.33 & 61.45 & 94.99 & & \\
\hline \multirow{2}{*}{ TBW [kg] } & yes & 159 & 31.83 & 3.85 & 31.30 & 21.00 & 51.60 & \multirow{2}{*}{0.66} & \multirow{2}{*}{ ns } \\
\hline & no & 127 & 31.21 & 2.82 & 31.00 & 22.60 & 39.80 & & \\
\hline \multirow{2}{*}{ TBW [\%] } & yes & 159 & 54.79 & 4.04 & 54.58 & 46.71 & 68.98 & \multirow{2}{*}{1.07} & \multirow{2}{*}{ ns } \\
\hline & no & 127 & 54.41 & 4.69 & 53.71 & 45.02 & 69.45 & & \\
\hline
\end{tabular}

* statistically significant, $\mathrm{p}<0.05$; ns - not statistically significant; SD — standard deviation

Source: authors' own research.

more prevalent in girls with normal BMI (Tab. 1) and with significantly lower FM, higher FFM and higher TBW.

Fat mass average in non-PMS women was approximately $3 \mathrm{~kg}$ higher than in PMS women. Also, non-PMS women had statistically lower fat-free mass and lower total body water (Tab. 2).

PMS women with $\mathrm{BMI} \geq 25 \mathrm{~kg} / \mathrm{m}^{2}$ had statistically higher fat-free mass (FFM, kg) and water (TBW, \%). No such statistical significance was found in women with $\mathrm{BMI}<25$.

The present findings are not consistent with the findings from several previous studies which concluded that PMS is more prevalent in obese women with $\mathrm{BMI}>30$ [14] and $\mathrm{BMI}>27.5 \mathrm{~kg}$ [15].
These previous studies have relied on the theory that in premenstrual period, glucose-induced metabolism of food deviates from the brain to the reproductive system and its surroundings including an increase in the level of blood in uterus vessels, which provides menstruation. Subsequently, this deviation leads to changes in brain control adjustment processes, which in turn cause impulsive symptoms characteristic of PMS. However, this hypothesis is not fully understood, because it has been proven that increased fat deposits compensate for a lack of metabolism required by the body and simply enhances glucose consumption. Since the premenstrual phase is characterized by a decrease in hormones in the bloodstream, no 


\begin{tabular}{|c|c|c|c|c|c|c|c|c|c|}
\hline \multirow{2}{*}{ Parameter } & \multirow{2}{*}{ PMS prevalence } & \multirow{2}{*}{$\mathbf{n}$} & \multirow{2}{*}{ Mean } & \multirow{2}{*}{ SD } & \multirow{2}{*}{ Median } & \multirow{2}{*}{ Min. } & \multirow{2}{*}{ Max. } & \multicolumn{2}{|c|}{ Mann-Whitney test* } \\
\hline & & & & & & & & Z & p \\
\hline \multirow{2}{*}{$\mathrm{FM}[\mathrm{kg}]$} & yes & 74 & 31.52 & 9.38 & 28.90 & 16.90 & 61.50 & \multirow{2}{*}{-0.52} & \multirow{2}{*}{ ns } \\
\hline & no & 116 & 31.54 & 8.64 & 30.60 & 15.20 & 61.70 & & \\
\hline \multirow{2}{*}{ FM [\%] } & yes & 74 & 37.85 & 5.85 & 36.95 & 19.30 & 50.10 & \multirow{2}{*}{-1.63} & \multirow{2}{*}{ ns } \\
\hline & no & 116 & 38.87 & 5.24 & 39.00 & 18.70 & 53.70 & & \\
\hline \multirow{2}{*}{ FFM [kg] } & yes & 74 & 50.58 & 6.62 & 49.75 & 38.50 & 70.50 & \multirow{2}{*}{2.33} & \multirow{2}{*}{$0.02^{*}$} \\
\hline & no & 116 & 48.45 & 5.34 & 47.15 & 39.60 & 65.90 & & \\
\hline \multirow{2}{*}{ FFM [\%] } & yes & 74 & 62.16 & 5.86 & 63.11 & 49.95 & 80.76 & \multirow{2}{*}{1.63} & \multirow{2}{*}{ ns } \\
\hline & no & 116 & 61.13 & 5.24 & 60.97 & 46.27 & 81.26 & & \\
\hline \multirow{2}{*}{ TBW [kg] } & yes & 74 & 37.03 & 4.85 & 36.40 & 28.20 & 51.60 & \multirow{2}{*}{2.34} & \multirow{2}{*}{$0.02^{*}$} \\
\hline & no & 116 & 35.47 & 3.90 & 34.55 & 29.00 & 48.20 & & \\
\hline \multirow{2}{*}{ TBW [\%] } & yes & 74 & 45.50 & 4.29 & 46.21 & 36.56 & 59.11 & \multirow{2}{*}{1.62} & \multirow{2}{*}{ ns } \\
\hline & no & 116 & 44.75 & 3.84 & 44.64 & 33.84 & 59.43 & & \\
\hline
\end{tabular}

*statistically significant, $\mathrm{p}<0.05$; ns - not statistically significant; SD — standard deviation

Source: authors' own research

significant increase in the function of the ovary and the uterus at the beginning of and during the next cycle is observed, and there is no clear reason for increased metabolic costs which are different during the premenstrual phase $[16,18]$. This theory partly explains the results of our research.

Moreover, it has to be noted that the cited authors $[14,15]$ previously conducted their studies on younger and older women aged 18-44. Our study group only included 18-hear-olds.

It is likely that obesity and being overweight will play a role in the etiology of PMS, although the relationship between PMS and anthropometric indicators in ambiguous. In some studies, BMI is directly or indirectly related to the body's hormonal balance mechanism [14, 19, 20, 22].

Most investigators relate PMS to the falling levels of progesterone during the luteal phase of the menstrual cycle, which leads to the lower oestrogen/progesterone ratio. One of the etiologic theories is related to fluid retention. The theory suggests that oestrogen induces increased hepatic angiotensinogen synthesis, which results in higher aldosterone levels. This in turn, leads to sodium retention and potassium-depleting effect. It has also been found that in PMS, there is little increase in prolactin levels in the luteal phase, which may be the result of abnormalities in the synthesis and the release of dopamine and serotonin. It has been proven that dopamine has a direct renal diuretic effect, whereas serotonin makes kidneys more sensitive [1, 2].

The feeling of pressure in the lower abdomen and low back pains result from fluid retention in the uterus and the venous stasis in the lesser pelvis. The swelling of central nervous system cells is the cause of headaches, dizziness, nausea, mental tension, insomnia, anxiety, tendency for depression and increased appetite. Weight gain by $2-4 \mathrm{~kg}$ resolves within the first days of menstruation [2].

The results of our study seem to confirm the fluid retention theory, since statistically significant differences were observed in the two study groups for total body water (TBW) in kilograms. Higher values were reported for PMS women $(p<0.005)$. This statistical significance was confirmed for both the whole study population and form women with $\mathrm{BMI} \geq 25 \mathrm{~kg} / \mathrm{m}^{2}$.

The pathophysiology of premenstrual syndrome is still unclear, and its causes may be of multifactorial nature.

Previous studies not very comprehensive assessed body composition in relation to PMS, it is impossible then to establish comparative and evolving nature of this relationship. Therefore, it is recommended that further studies should be conducted to confirm correlations between the prevalence of PMS and body composition expressed as fat mass, fat free mass and total body water content. In order to develop and understanding of their importance for future treatment of women with PMS.

A limited number of previous studies have evaluated the relationship between body mass index body composition and premenstrual syndrome and to our knowledge, this is the first study that has investigated the relationship between PMS prevalence, state of nutrition and body composition in developmental age girls. Further study is recommended to determine the optimal BMI and fat mass values, which will help minimize PMS prevalence.

\section{CONCLUSIONS}

Although the pathophysiology behind PMS has not been fully explained, it is recommended to assess the state 
of nutrition and body composition which, as the current study shows, are related to premenstrual syndrome prevalence. Since they are modifiable factors, PMS treatment should include a balanced diet and physical activity, which will help to modify not only body mass but also fat mass. Further studies on PMS women should also offer recommendations for lifestyle interventions.

It is also vital to ensure that PMS-related psychosexual disorders are diagnosed, and proper treatment is administered.

The strengths of our study include sample size (476 women) and its homogeneity (all the patients were Caucasian women aged 18). A limitation of the study is that we did not analyze lifestyle factors such as diet, physical activity and the use of stimulants, all of which may be potentially linked to PMS prevalence.

\section{Conflict of interests}

The authors declare no conflict of interests.

\section{REFERENCES}

1. Dżygadło B, Łepecka-KlusekC, Pilewski B. Use of bioelectrical impedance analysis in prevention and treatment of overweight and obesity. Probl Hig Epidemiol. 2012; 93(2): 274-280.

2. Stanowisko Zespołu Ekspertów Polskiego Towarzystwa Ginekologicznego w sprawie zastosowania leku Mastodynon w ginekologii. Ginekol Pol. 2013; 84: 157-159.

3. Green LJ, O'Brien PMS, Panay N, et al. on behalf of the Royal College of Obstetricians and Gynaecologists. Management of premenstrual syndrome. BJOG. 2017; 124: e73-e105.

4. Wan CS, Ward LC, Halim J, et al. Bioelectrical impedance analysis to estimate body composition, and change in adiposity, in overweight and obese adolescents: comparison with dual-energy $\mathrm{x}$-ray absorptiometry. BMC Pediatr. 2014; 14: 249, doi: 10.1186/1471-2431-14-249, indexed in Pubmed: 25280868.

5. Negi P, Mishra A, Lakhera P. Menstrual abnormalities and their association with lifestyle pattern in adolescent girls of Garhwal, India. J Family Med Prim Care. 2018; 7(4): 804-808, doi: 10.4103/jfmpc.jfmpc_159_17, indexed in Pubmed: 30234057.

6. Fisher C, Adams J, Frawley J, et al. Is there a role for Western herbal medicine in treating cyclic perimenstrual pain and discomfort? Australian and New Zealand Journal of Obstetrics and Gynaecology. 2018; 59(1): 154-156, doi: 10.1111/ajo.12883.

7. Arslantaş $\mathrm{H}$, Abacigil $\mathrm{F}$, Çinakli Ş. Relationship between premenstrual syndrome and basic personality traits: a cross-sectional study. Sao Paulo
Med J. 2018; 136(4): 339-345, doi: 10.1590/1516-3180.2018.0061240418, indexed in Pubmed: 30110077.

8. Armour M, Ee CC, Hao J, et al. Acupuncture and acupressure for premenstrual syndrome. Cochrane Database Syst Rev. 2018; 8: CD005290, doi: 10.1002/14651858.CD005290.pub2, indexed in Pubmed: 30105749.

9. Olajossy M, Gerhant A. Zespół napięcia przedmiesiączkowego i przedmiesiączkowe zaburzenia dysforyczne - problem z pogranicza psychiatrii i ginekologii. Curr Probi Psychiatry. 2011; 12(2): 163-170.

10. Sadler C, Smith $\mathrm{H}$, Hammond J, et al. Southampton Women's Survey Study Group. Lifestyle factors, hormonal contraception, and premenstrual symptoms: the United Kingdom Southampton Women's Survey. J Womens Health (Larchmt). 2010; 19(3): 391-396, doi: 10.1089/jwh.2008.1210, indexed in Pubmed: 20156129.

11. Watanabe K, Shirakawa T. Characteristics of Perceived Stress and Salivary Levels of Secretory Immunoglobulin A and Cortisol in Japanese Women With Premenstrual Syndrome. Nurs Midwifery Stud. 2015; 4(2): e24795, doi: 10.17795/nmsjournal24795, indexed in Pubmed: 26339665.

12. Pałucka K, Łepecka-Klusek C, Pilewska-Kozak A, et al. Premenstrual syndrome - myth or reality. Journal of Education, Health and Sport. 2016; 6(6): 478-490

13. Masho SW, Adera T, South-Paul J. Obesity as a risk factor for premenstrual syndrome. J Psychosom Obstet Gynaecol. 2005; 26(1): 33-39, indexed in Pubmed: 15962720.

14. Bertone-Johnson ER, Hankinson SE, Willett WC, et al. Adiposity and the development of premenstrual syndrome. J Womens Health (Larchmt). 2010; 19(11): 1955-1962, doi: 10.1089/jwh.2010.2128, indexed in Pubmed: 20874240.

15. Management of Premenstrual Syndrome. BJOG: An International Journal of Obstetrics \& Gynaecology. 2016; 124(3): e73-e105, doi: 10.1111/14710528.14260.

16. Zendehdel M, Elyasi F. Biopsychosocial etiology of premenstrual syndrome: A narrative review. J Family Med Prim Care. 2018; 7(2): 346-356, doi: 10.4103/jfmpc.jfmpc_336_17, indexed in Pubmed: 30090776.

17. Yonkers KA, O'Brien PM, Eriksson E. Premenstrual syndrome. Lancet. 2008; 371: 1200-1210.

18. Gillings MR. Were there evolutionary advantages to premenstrual syndrome? Evol Appl. 2014; 7(8): 897-904, doi: 10.1111/eva.12190, indexed in Pubmed: 25469168.

19. Haghighi ES, Jahromi MK, Daryano Osh F. Relationship between cardiorespiratory fitness, habitual physical activity, body mass index and premenstrual symptoms in collegiate students. J Sports Med Phys Fitness. 2015; 55(6): 663-667, indexed in Pubmed: 26205766.

20. Rad M, Sabzevary MT, Dehnavi ZM. Factors associated with premenstrual syndrome in Female High School Students. J Educ Health Promot. 2018; 7: 64, doi: 10.4103/jehp.jehp_126_17, indexed in Pubmed: 29922693.

21. Yamada K, Takeda T. Low Proportion of Dietary Plant Protein among Athletes with Premenstrual Syndrome-Related Performance Impairment. Tohoku J Exp Med. 2018; 244(2): 119-122, doi: 10.1620/tjem.244.119, indexed in Pubmed: 29434077.

22. Mohammadi V, Shidfar F, Keshtkar Ag, et al. The relationship of antrhropometric indices with PMS and it's severity in female students of Tehran University of medical sciences. Raxi J Med Sci. 2013; 20: 87-94. 